\title{
Kuka hyötyisi sikatilojen tautiriskiluokittelusta?
}

\author{
Jarkko K. Niemi ${ }^{1)}$, Tapani Lyytikäinen ${ }^{2)}$, Leena Sahlström ${ }^{2)}$, Terhi Virtanen ${ }^{2)}$ ja Heikki Lehtonen ${ }^{1)}$ \\ ${ }^{1)}$ MTT taloustutkimus, Luutnantintie 13,00410Helsinki,jarkko.niemi@mtt.fi,heikki.lehtonen@mtt.fi \\ ${ }^{2)}$ Evira, Riskinarviointi, Mustialankatu 3,00790 Helsinki, tapani.lyytikainen@evira.fi, \\ leena.sahltrom@evira.fi,terhi.virtanen@evira.fi
}

\section{Tiivistelmä}

Herkästi tarttuvat eläintaudit, kuten suu- ja sorkkatauti, voivat Suomeen levitessään aiheuttaa mittavaa taloudellista vahinkoa. Menetyksiä aiheuttavat mm. taudin hävittämiseen liittyvien toimenpiteiden kustannukset ja kansainväliseen kauppaan liittyvien rajoitusten riski. On tärkeää kohdistaa riskinhallintatoimenpiteet siten, että ne estävät tarpeettomat taloudelliset menetykset. Tässä voi auttaa kotieläintilojen riskiluokittelu niiden taudinlevittämiskyvyn mukaan.

Tutkimuksessa selvitettiin, miten sikatilan riski levittää suu- ja sorkkatautia vaikuttaa tautipurkauksen sikasektorille aiheuttamiin taloudellisiin menetyksiin. Tässä keskitytään sikatiloihin rajoittuvaan tautipurkaukseen, koska sikatalous on pitkälle eriytynyt ja vain harvalla sikatilalla on muita eläimiä. Siat eivät ole taipuvaisia saamaan tartuntaa ilmavälitteisesti.

Suu- ja sorkkataudin leviämistä sikatilojen välillä arvioitiin Monte Carlo-simulaatiomallilla ja tautipurkauksen mahdollisia taloudellisia vaikutuksia sikamarkkinoihin arvioitiin osittaisen tasapainon mallilla. Taudin leviäminen oletettiin mahdolliseksi naapurileviämisenä alle $3 \mathrm{~km}$ säteelle tartuntatilasta sekä tartuntatilalta lähtevän eläinkuljetuksen, eläinkuljetusajoneuvon tai eläinsuojassa tai tilalla käyvän ihmisen välityksellä. Taloudelliset vaikutukset simuloitiin kuluttajille, tuottajille (ml.. teurastamot) ja veronmaksajille. Tilat luokiteltiin klusterianalyysilla neljään ryhmään (pieni, keskisuuri, suuri tai erittäin suuri riski) sen mukaan, miten vakavia tiloilta alkaneet tautipurkaukset olivat.

Erittäin suuren riskiluokan tiloilla oli yleensä enemmän eläinkontakteja ja ne sijaitsivat eläintiheämmällä alueella kuin pienen riskiluokan tilat. Muun muassa nämä tekijät lisäävät tilan riskiä levittää tautia. Tilan todennäköisyys levittää tauti toiselle sikatilalle vaikutti tilojen välisiin eroihin menetyksissä. Vaihtelu menetyksissä oli suurta. Pienen tautiriskin tilalta alkava tautipurkaus aiheutti yhteiskunnalle keskimäärin 18 miljoonan euron menetykset. Erittäin suuren riskiluokan tiloilta alkaneiden tautipurkausten aiheuttama menetys oli keskimäärin 26 miljoonaa euroa. Tuottajien menetykset olivat pienen riskin tiloilta alkaneissa tautipurkauksissa keskimäärin 23 miljoonaa euroa ja suuren riskin tilalta alkaneissa tautipurkauksissa 28 miljoonaa euroa. Suhteellisesti voimakkaimmin kasvoivat verovaroista maksettavat kustannukset. Erittäin suuren riskiluokan tiloilla ne olivat 4 miljoonaa euroa, mikä oli 18 kertaa enemmän kuin pienen riskiluokan tiloilla. Kuluttajien hyöty tilapäisesti alemmista hinnoista väheni kun riskiluokka kasvoi.

Tulokset viittaavat siihen, että etenkin pienen riskin tilat ja veronmaksajat hyötyisivät, mikäli tiukimmat taudin leviämistä ennaltaehkäisevät riskinhallintatoimenpiteet kohdennettaisiin ensi sijassa suuren riskin tiloille. Pitkällä aikavälillä myös kuluttajat voisivat hyötyä. Riskiluokittelutietoa voidaan hyödyntää kohdennettaessa riskinhallintatoimenpiteitä ja mahdollisesti määriteltäessä tilojen riskiperusteista vastuuta tautivahingoista.

Asiasanat: Eläintaudit, sika, riskiluokittelu, simulointi, kysyntä, tarjonta, vienti, tappiot 


\section{Johdanto}

Herkästi tarttuvan eläintaudin leviäminen Suomeen voi aiheuttaa mittavaa taloudellista vahinkoa yksittäisille yrityksille ja kansantaloudelle. Esimerkiksi suu- ja sorkkataudin ja klassisen sikaruton kaltaisten eläintautien kohdalla tuotantorakennusten desinfioinnin, kontaminoituneen materiaalin hävityksen, tartuntojen havaitsemiseksi tehtävien tarkastusten ja muiden taudin havaitsemiseen ja maasta hävittämiseen tähtäävien toimenpiteiden kustannukset voivat nousta suuriksi. Tätäkin merkittävämpiä ovat yleensä taudinpurkauksen välilliset vaikutukset, kuten elintarvikeviennin häiriöiden seuraukset tai eläinten hyvinvointiongelmien aiheuttamat kustannukset (mm. Franks ym. 2001, Mangen ja Burrell 2003, Schoenbaum ja Disney 2003).

On tärkeää kohdistaa eläintautiriskinhallinnan toimenpiteet siten, että ne estävät tarpeettomat taloudelliset menetykset. Tutkimustulosten mukaan kotieläintuotannon rakenne ja toimintatavat alueella, jonne tauti pääsee leviämään, vaikuttavat taudin leviämiseen (mm. Raulo ja Lyytikäinen 2005, Lyytikäinen ja Kallio 2008, Ortiz-Pelaez ym. 2006, Ribbens ym. 2009). On myös viitteitä siitä, että tuotantorakenne vaikuttaa taloudellisiin menetyksiin (esim. Mangen ja Burrell 2003, Niemi ym. 2008). Ei kuitenkaan ole tutkittu, miten ensimmäisenä maassa tartunnan saaneen tilan ominaisuudet vaikuttavat taudinpurkauksen aiheuttamiin menetyksiin. Riskinhallintatoimenpiteiden kohdentamiseksi on tärkeää tietää, miten suuria menetyksiä kultakin tilalta alkavat taudinpurkaukset aiheuttavat.

Kotieläintilojen riskiluokittelu voi auttaa kohdistamaan riskinhallinnan resursseja taloudellisesti tehokkaalla tavalla. Tässä tutkimuksessa selvitettiin, miten sikatilan riski levittää suu- ja sorkkatautia vaikuttaa tautipurkauksen Suomen sikasektorille aiheuttamiin taloudellisiin menetyksiin. Tutkimusaineistona oli rekisteritietoja, tiloilta ja alan toimijoilta kerättyjä tietoja, tilastoaineistoa lihan kulutuksesta, viennistä, hinnoista, tuotantokustannuksista ja taudin hävityksen resurssitarpeista. Tutkimusmenetelminä käytettiin Monte Carlo-simulointia, numeerista dynaamista osittaisen tasapainon mallia ja simulaatiotuloksiin sovellettua klusterianalyysia. Tässä keskitytään sikatiloihin rajoittuvaan tautipurkaukseen, koska sikatalous on pitkälle eriytynyt ja vain harvalla sikatilalla on muita eläimiä. Siat eivät ole taipuvaisia saamaan tartuntaa ilmavälitteisesti.

\section{Aineisto ja menetelmät Epidemiologinen simulaatiomalli}

Suu- ja sorkkataudin leviämistä sikatilojen välillä arvioitiin Lyytikäisen ja Kallion (2008) kuvaamalla Monte Carlo-simulaatiomallilla. Malli tuottaa kussakin iteraatiossa tartunnan saaneiden tilojen lukumäärän, tartuntatilojen tunnistetiedot sekä taudinpurkauksen keston. Taudin leviämistä simuloidaan todellisissa havaituissa verkostoissa. Verkostomalli sopii eri mallityypeistä parhaiten taudinleviämisen simulointiin, koska tautia levittäviä tapahtumia esiintyy verraten harvoin ja kontaktit ja kontaktien kohteet ovat eri tavoin ajallisesti ja paikallisesti keskittyneitä ja toisistaan eriytyneitä. Taudin leviäminen oletettiin mahdolliseksi naapurileviämisenä alle $3 \mathrm{~km}$ säteelle tartuntatilasta sekä tartuntatilalta lähtevän eläinkuljetuksen, eläinkuljetusajoneuvon tai eläinsuojassa tai tilalla käyvän ihmisen välityksellä.

Malli parametrisoitiin vuoden 2006 tiedoilla ja se kuvaa tilannetta, jossa Suomen sikatiloille olisi levinnyt suu- ja sorkkatauti vuonna 2006. Taudin ominaisuuksia kuvaavat tunnusluvut perustuivat aikaisempiin tutkimuksiin (mm. Stevenson 2003, Taylor ym. 2004). Mallissa taudin leviämisreitit kuvattiin rekisteri- ja kyselytietojen avulla. Eläinkuljetusten osalta verkostokuvaus sisältyy eläinkuljetus- ja tilarekistereihin, jotka kuvaavat eläinsiirtojen tapahtuma-ajat, eläinten alkuperän ja päätymispaikan. Naapurileviämisen osalta verkostokuvaus perustuu tilojen sijaintikoordinaatteihin.

Taudin leviämistä ehkäisevät ja sen hävittämiseen tähtäävät toimenpiteet perustuvat suu-ja sorkkatautidirektiivin (Euroopan Komissio 2003). Tutkimusta varten simuloitiin 0,9 miljoonaa taudinpurkausta, joita simuloitiin aloittaen jokaiselta suomalaiselta sikatilalta. Jatkoanalyysissa kullekin maassa ensimmäisenä tartunnan saaneelle tilalle ( $\mathrm{n}=3228$ tilaa) käytettiin siltä alkaneiden taudinpurkausten keskiarvotulosta.

\section{Osittaisen tasapainon malli ja taloudelliset menetykset}

Taudinpurkauksen vaikutus kuluttajien (sis. kauppa) ja tuottajien (sis. teurastamot) taloudelliseen ylijäämään maksettavat tappiot mallinnettiin dynaamisella osittaisen tasapainon mallilla. Lisäksi laskettiin verovaroista maksettavat suorat tappiot. Taloudelliset vaikutukset laskettiin kullekin ensimmäisenä tartunnan saaneelle tilalle erikseen käyttäen sille simuloitua keskiarvotaudinpurkausta.

Tasapainomalli simuloi sikamarkkinoiden toimintaa kuukausitasolla. Lyhyen aikajänteen huomioon ottaminen on tärkeää ilmiön kuvaamiseksi realistisesti, sillä lyhyellä aikavälillä tuottajien mahdollisuudet 
sopeuttaa tuotantoa ovat rajalliset. Malli maksimoi sikatuotannosta saatavan kuluttajien ja tuottajien taloudellisen ylijäämän ja siten minimoi taudinpurkauksesta aiheutuvat välilliset menetykset. Malli ratkaisee sianlihan kysynnän ja tarjonnan sekä näitä vastaavan markkinat tyhjentävän tasapainohinnan endogeenisesti. Markkinoilla vaihdettu määrä ratkaistaan optimoimalla emakoiden siemennysmäärät sekä lihasikojen teuraspainot. Sianlihankysyntä jaetaan neljään osaan, jotka olivat suomalaisen sianlihan kysyntä kotimaassa, muissa EU-maissa sekä EU:n ulkopuolisilla vientimarkkinoilla, ja sianlihan tuontikysyntä Suomessa. Kotimainen ja tuontisianliha oletettiin epätäydellisiksi substituuteiksi. Kysyntäjoustot estimoitiin kokonaiskysynnälle kolmitasoisella pienimmän neliösumman menetelmällä. Siten estimoinnissa otettiin huomioon, että suomalaisen sianlihan hinta voi olla mallissa endogeeninen ja että kysyntäyhtälöiden virhetermit voivat korreloida keskenään. Tuotantokustannusrakenne perustui ProAgrian (2007) tilamallilaskelmiin sekä lihasikatuotannon osalta osittain myös Niemen (2006) esittämään siankasvumalliin.

Mallissa taudinpurkauksesta seuraa sianlihan viennin keskeytyminen. Vientihäiriön kesto on ensimmäisen tautihavainnon ja viimeisten rajoittavien määräysten poistamisen välinen aika lisättynä kolmella kuukaudella. Skenaario perustuu siten epidemiologisiin simulaatioihin ja eläintautijärjestö OIE:n suosituksiin (OIE 2007). Vientihäiriön kesto oli kuitenkin stokastinen siten, että kansainvälisten kauppakumppanien suhtautumisesta riippuva keskimäärin kolmen kuukauden varoaika saattoi päättyä aikaisemmin tai myöhemmin kuin kolme kuukautta viimeisten rajoittavien määräysten poistamisesta. Vientimahdollisuuksien palautuminen noudatti Poisson-jakaumaa.

Jokaisella hetkellä sikamarkkinoita voitiin kuvata kolmella tilannemuuttujalla, jotka olivat tuotannossa olevien emakoiden lukumäärä, kasvatettavana olevien lihasikojen ja porsaiden lukumäärä sekä vientimarkkinoiden tilanne (vienti mahdollista tai vienti estetty). Taudinpurkauksesta aiheutuvat menetykset laskettiin arvofunktion erotuksena tilanteissa, joissa vienti on ja ei ole mahdollista Niemi ja Lehtonen (2008) kuvaavat mallin yksityiskohtaisemmin.

Epidemiologisista simulaatioista ja tilarekisteriaineistosta määritettiin suu-ja sorkkatautipurkauksen vaikutus tiloilla olevien eläinten määrään, rajoittava vaikutus emakoiden siemennyksiin suojavyöhykkeillä ja siten tuotantoon sekä laskettiin taudin hävittämisestä aiheutuvat suorat kustannukset. Suorilla kustannuksilla tarkoitettiin verovaroista korvattavia kustannuksia, kuten tartunnan saaneiden eläinten lopetuksen ja hävityksen kustannuksia, tiladesinfektioiden kustannuksia, näytteenotosta, tilojen tarkastuksista ja muusta viranomaisten toiminnasta aiheutuvia välittömiä kustannuksia. suorien kustannusten laskennassa hyödynnettiin Iso-Britannian vuoden 2001 taudinpurkauksesta kerättyjä tietoja (Risk Solutions 2005), eläinlääkäreille laadittuja toimintaohjeita sekä MTT:n ja Eviran tutkimusta (Niemi ym. 2008).

\section{Klusterianalyysi}

Tilat luokiteltiin K-means-klusterianalyysilla neljään ryhmään (pieni, keskisuuri, suuri tai erittäin suuri riski) Lyytikäisen ja Kallion (2008) menettelyn mukaan. Tilojen luokittelu perustui siihen, miten vakavia tiloilta alkaneet tautipurkaukset olivat. Tautipurkauksen vakavuutta tarkasteltiin tilalta alkaneiden epidemioiden keston, keskimäärin ja enimmillään tartunnan saaneiden tilojen lukumäärän, sekä epidemian esiintymistodennäköisyyden perusteella, silloin kun tila olisi ensimmäinen tartunnan saanut tila Suomessa.

\section{Tulokset ja tulosten tarkastelu}

Ensimmäisenä tartunnan saanut tila aiheutti epidemian 66 prosentin todennäköisyydellä. Keskimäärin tartuntatiloja oli 4,1 (vaihteluväli 1-22 tilaa). Taudinpurkaus kesti keskimäärin vain 38 päivää, 229 emakkoa ja 1602 lihasikaa lopetettiin ja 57 sikatilaa, 3463 tartunnan saamatonta emakkoa ja 19251 lihasikaa joutui suoja- ja valvontavyöhykkeille. Keskimäärin tilalta alkanut tautipurkaus aiheutti tuottajille 26 miljoonan euron menetykset ja veronmaksajille vajaan 2 miljoonan euron kustannukset. Sen sijaat kuluttajat ja kauppa pääsivät hyötymään ylitarjonnan vuoksi alentuneista hinnoista 6 miljoonaa euroa, jolloin yhteiskunnan kokonaismenetysten simuloitiin nousevan 21 miljoonan euroon.

Erittäin suuren riskiluokan tiloilla oli yleensä enemmän eläinkontakteja ja ne sijaitsivat eläintiheämmällä alueella kuin pienen riskiluokan tilat. Muun muassa nämä tekijät lisäävät tilan riskiä levittää tautia. Tilan todennäköisyys aiheuttaa epidemia korreloi menetysten ja niihin vaikuttavien tekijöiden kanssa siten, että todennäköisyyden avulla voitiin selittää 67 prosenttia tilojen välisistä eroista menetyksissä.

Vaihtelu samaankin riskiluokkaan kuuluvien tilojen aiheuttamissa menetyksissä oli suurta. Pienen tautiriskin tilalta alkava tautipurkaus aiheutti yhteiskunnalle keskimäärin 18 miljoonan euron menetykset. Erittäin suuren riskiluokan tiloilta alkaneiden tautipurkausten aiheuttama menetys oli keskimäärin 26 mil- 
joonaa euroa. Tuottajille aiheutuneet menetykset olivat pienen riskin tiloilta alkaneissa tautipurkauksissa keskimäärin 23 miljoonaa euroa ja suuren riskin tilalta alkaneissa tautipurkauksissa 28 miljoonaa euroa (Kuva 1). Suhteellisesti laskien voimakkaimmin kasvoivat verovaroista maksettavat kustannukset. Erittäin suuren riskiluokan tiloilla ne olivat 4 miljoonaa euroa, mikä oli 18 kertaa enemmän kuin pienen riskiluokan tiloilla. Kuluttajien hyöty tilapäisesti alemmista hinnoista aleni kun riskiluokka kasvoi.

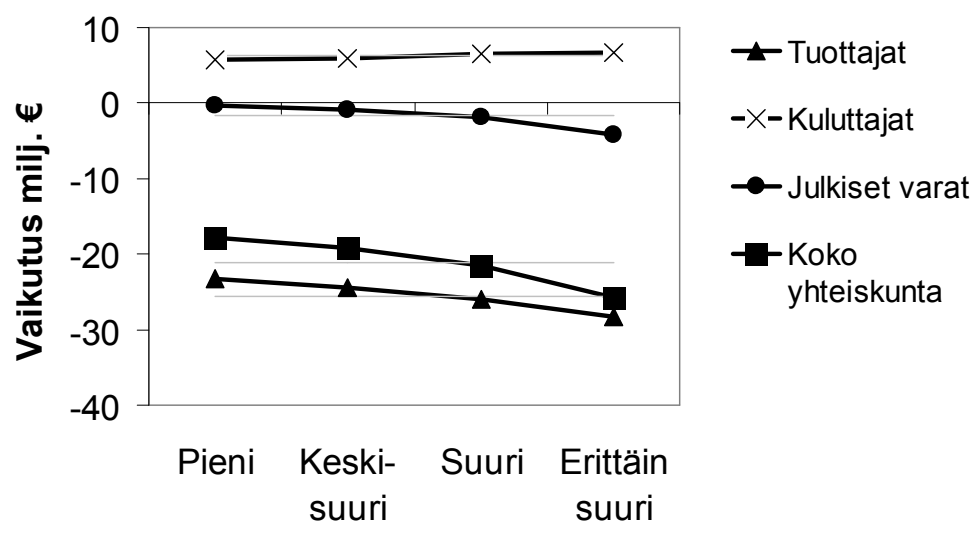

Ensimmäisen tartuntatilan riskiluokka

Kuva 1. Ensimmäisenä tartunnan saaneen tilan riskiluokan yhteys kuluttajien ja tuottajien taloudellisen ylijäämän muutokseen, julkisista verovaroista maksettaviin kustannuksiin sekä yhteiskunnalle aiheutuviin taloudellisiin menetyksiin. Harmaat viivat kuvaavat kaikkien tilojen keskiarvoa ilman luokittelua.

\section{Johtopäätökset}

Tulokset viittaavat siihen, että etenkin pienen riskin tilat ja veronmaksajat hyötyisivät, mikäli tiukimmat taudin leviämistä ennaltaehkäisevät riskinhallintatoimenpiteet kohdennettaisiin ensi sijassa suuren riskin tiloille. Pitkällä aikavälillä myös kuluttajat voisivat hyötyä. Riskiluokittelutietoa voidaan hyödyntää kohdennettaessa riskinhallintatoimenpiteitä ja mahdollisesti määriteltäessä tilojen riskiperusteista kustannusvastuuta tautivahingoista.

\section{Kirjallisuus}

Euroopan Komissio. 2003. Council Directive 2003/85/EC of 29 September 2003 on Community measures for the control of foot-and-mouth disease repealing directive 85/511/EEC and decisions 89/531/EEC and 91/665/EEC and amending directive 92/46/EEC. Official Journal of the European Union L306:1-87.

Franks, J., Lowe, P., Phillipson, J. \& Scott, C. 2001. The impact of foot and mouth disease on farm businesses in Cumbria. Land Use Policy 20: 159-168.

Lyytikäinen, T. \& Kallio, E. 2008. Risk classification of Finnish pig farms by simulated foot and mouth disease spread. Julkaisussa: Peeler, E.J., Alban, L., Russell, A. and the SVEPM Executive Committee, Eds. Society for Veterinary Epidemiology and Preventive Medicine, Proceedings of a meeting held at Liverpool, UK 26th-28th of March 2008. pp. 285-300.

Mangen, M.-J.J. \& Burrell, A.M. 2003. Who gains, who loses? Welfare effects of classical swine fever epidemics in the Netherlands. European Review of Agricultural Economics 30:125-154.

Niemi, J.K. 2006. Dynamic programming model for optimising feeding and slaughter decisions regarding fattening pigs. Agricultural and Food Science 15, Supplement. 1: 1-121. Saatavilla Internetissä: http://urn.fi/URN:ISBN:951729-997-4.

Niemi, J.K. \& Lehtonen, H. 2008. The value of market uncertainty in a livestock epidemic. Poster paper presented at AAEA annual meeting, Orlando, FL, 27-29 July 2008. Saatavilla Internetissä: http://purl.umn.edu/6158.

Niemi, J.K., Lehtonen, H., Pietola, K., Lyytikäinen, T. \& Raulo, S. 2008. Economic implications of potential classical swine fever outbreaks for Finnish pig production sector. Preventive Veterinary Medicine 84: 194-212.

OIE. 2007. Terrestrial animal health code. 2007. Office International des Epizooties, Paris.

Ortiz-Pelaez, A., Pfeiffer, D.U, Soares-Magalhaes, R.J. \& Guitian, F.J. 2006. Use of social network analysis to characterize the pattern of animal movements in the initial phases of the 2001 foot and mouth disease (FMD) epidemic in the UK. Preventive Veterinary Medicine 76: 40-55.

ProAgria. 2007. Tuottopehtoori. ProAgria keskusten liitto, Vantaa. Viitattu 18.2.2009. Saatavilla Internetissä: http://www.agronet.fi/cgi-bin/mkl/julk/malli.cgi. 
Raulo, S. \& Lyytikäinen, T. 2005. Klassisen sikaruton epideeminen taudinpurkaus Suomessa - kvantitatiivinen riskinarviointi. EELAn julkaisuja 06/2005. Eläinlääkintä- ja elintarviketutkimuslaitos, Helsinki. $192 \mathrm{~s}$.

Ribbens, S., Dewulf, J., Koenen, F., Mintiens, K., de Kruif, A. \& Maes, D. 2009. Type and frequency of contacts between Belgian pig herds. Preventive Veterinary Medicine 88: 57-66.

Risk Solutions. 2005. FMD CBA epidemiological model specification and description. A report for Defra, May 2005. Viitattu 30.4.2009. Saatavilla Internetissä:

http://www.defra.gov.uk/animalh/diseases/fmd/pdf/epidem_model.pdf.

Schoenbaum, M. A. and Disney, W. T. 2003. Modeling alternative mitigation strategies for a hypothetical outbreak of foot-and-mouth disease in the United States. Preventive Veterinary Medicine 58: 25-52.

Stevenson, M.A. 2003. The spatio-temporal epidemiology of bovine spongiform encephalopathy and foot-andmount disease in Great Britain. Ph.D. Thesis. Institute of Veterinary, Animal and Biomedical Sciences, Massey University, Palmerston, New Zealand. 249 p.

Taylor, N.M, Honhold, N, Paterson, A.D. \& Mansley, L.M. 2004. Risk of foot-and-mouth disease associated with proximity in space and time to infected premises and the implications for control policy during the 2001 epidemic in Cumbria. Veterinary Record 155: 646-647. 